\title{
Synthesis, Characterization, X-Ray
} Crystallography, and Antileishmanial Activities of $\boldsymbol{N}$-Linked and $\boldsymbol{O}$-Linked Glycopyranosides

\author{
Haroon ur Rashid $\left(D,{ }^{1}\right.$ Sher Wali Khan $(D),{ }^{2}$ Momin Khan, ${ }^{3,4}$ Akhtar Nadhman, \\ Noor Rehman, ${ }^{2}$ Muhammad Tariq, ${ }^{2}$ and Sammer Yousuf $\mathbb{i D}^{6}$ \\ ${ }^{1}$ Department of Chemistry, Sarhad University of Science and Information Technology, Peshawar, Khyber Pakhtunkhwa, Pakistan \\ ${ }^{2}$ Department of Chemistry, Shaheed BB University, Sheringal, Upper Dir, Khyber Pakhtunkhwa, Pakistan \\ ${ }^{3}$ Department of Biotechnology, Quaid-I-Azam University, Islamabad 45320, Pakistan \\ ${ }^{4}$ Department of Microbiology, Institute of Basic Medical Sciences, Khyber Medical University, Peshawar, Pakistan \\ ${ }^{5}$ Institute of Integrative Biosciences (IIB), CECOS University of Information Technology and Emerging Sciences, Peshawar, \\ Khyber Pakhtunkhwa, Pakistan \\ ${ }^{6}$ H. E. J. Research Institute of Chemistry, International Center for Chemical and Biological Sciences, University of Karachi, \\ Karachi 75270, Pakistan \\ Correspondence should be addressed to Sher Wali Khan; sherwalikhn@yahoo.co.uk
}

Received 1 August 2017; Revised 14 November 2017; Accepted 7 December 2017; Published 30 January 2018

Academic Editor: Vinod Kumar Tiwari

Copyright (C) 2018 Haroon ur Rashid et al. This is an open access article distributed under the Creative Commons Attribution License, which permits unrestricted use, distribution, and reproduction in any medium, provided the original work is properly cited.

Novel $N$-linked $5 \mathbf{a}-\mathbf{e}$ and $O$-linked glycopyranosides $7 \mathbf{a}-\mathbf{e}$ were synthesized in high yield from commercially available L-tartaric acid containing two asymmetric centers and $C_{2}$ axis of symmetry. The compound L-tartaric acid was completely protected and then partially hydrolyzed to get the monoester, which upon treatment with different amino and hydroxyl derivatives of glycopyranoses gave the desired amides and esters. The synthesized derivatives were purified by chromatography and characterized by spectroanalytical techniques. The structure of compound $7 \mathrm{c}$ in the series was supported by X-ray analysis. Leishmanicidal activities of compounds $\mathbf{5 a}-\mathbf{e}$ and $\mathbf{7 a}-\mathbf{e}$ were investigated which showed moderate to good activities.

\section{Introduction}

Leishmania has long been known to human beings especially in African and Indian populations since the mid eighteenth century [1-3]. In 1903, Leishman and Donovan discovered the protozoan in spleen tissues of patients in India, which is now known as Leishmania donovani $[4,5]$. Nicolle and Comte reported infection by Leishmania in dogs in 1908 [6]. Leishmaniasis is a vector-borne disease carried by sand fly and caused by protozoa of the genus Leishmania. Recent reports confirm that people in about 88 countries are affected by Leishmania and 350 million are at risk, and more or less 2 million new cases are reported each year [7]. In spite of the socioeconomical significance of this tropical infectious disease, the discovery of new potential drugs against it is underway $[8,9]$.

Glycolipid and glycoprotein oligosaccharides present on cell surfaces are known to play an important role in various biological processes, that is, cellular recognition, adhesion, tumor metastasis, and cell growth regulation [10]. One major class of glycoprotein oligosaccharides consists of $\mathrm{N}$ oligosaccharides linked to asparagine by an amide bond [11, 12]. Amides are usually prepared by thermolysis of carboxylic acids with amines, by coupling of carboxylic acids and amines in the presence of a coupling reagent [13] or by prior conversion of the carboxylic acid into a more electrophilic derivative [14]. The concept to add a chiral aglycone moiety such as tartaric acid to prepare glycosides is an active area 
of research. L-tartaric acid is cheap and readily available starting material; it has two chiral centers with two carboxylic acid groups which can be easily derivatized. Derivatives of tartaric acid containing ester and amide linkages have promisingly useful biological applications, for example, antiinflammatory, antifungal, thrombin inhibitors, antimicrobial, and $\beta$-secretase inhibitory activities [15-20].

Hence, glyco derivatives of tartaric acid have potential as curative agents for various infectious diseases. Herein, we report an efficient and scalable synthesis of $N$-linked (5a-e) and $O$-linked glycopyranosides $(7 \mathbf{a}-\mathbf{e})$ through anomeric $N$ and $\mathrm{O}$-acylation, respectively, using commercially available L-tartaric acid as a starting material.

\section{Experimental}

All chemicals were of highest purity available and used as supplied. D-glucose, D-mannose, D-galactose, D-glucosamine, and D-galactosamine hydrochloride were purchased from Fluka and Sigma Aldrich. Dry solvents like methanol, dichloromethane, chloroform, and n-hexane were obtained by distillation using standard procedures or by passage through a column of anhydrous alumina using equipment from anhydrous engineering (University of Bristol, UK) based on Grubbs' design. Reactions under anhydrous conditions were carried out under nitrogen gas using three-way stopcock and rubber septa.

Liquid reagents, solutions, or solvents were added via syringe or cannula through rubber septa. Solid reagents were added via Schlenk type adapters. All reactions were monitored by TLC on Kieselgel 60 F254 (Merck); ethyl acetate/nhexane and methanol/chloroform were used as eluent. Chromatograms were detected under UV light $\left(\lambda_{\max } 254\right.$ and $365 \mathrm{~nm}$ ) and by charring with $10 \%$ sulfuric acid in ethanol, ninhydrin, and vanillin, respectively. Column chromatography was performed using silica gel [Merck, 230-400 mesh $(40-63 \mu \mathrm{m})]$. Extracts were concentrated under reduced pressure using both rotary evaporator (bath temperature up to $40^{\circ} \mathrm{C}$ ) at a pressure of either $15 \mathrm{mmHg}$ (diaphragm pump) or $0.1 \mathrm{mmHg}$ (oil pump), as appropriate and a high vacuum line at room temperature. Melting points were determined in degree Celsius $\left({ }^{\circ} \mathrm{C}\right)$ using Gallenkamp digital melting point apparatus and are uncorrected. IR spectra were recorded on a Bruker IFS 66 (FT-IR), Nicolet 205 FT-IR; Nicolet 360 smart orbit (ATR); Thermo Scientific Nicolet 6700 FT-IR and Shimadzu Fourier Transform Infrared Spectrophotometer Model 270. Solid samples were taken in $\mathrm{KBr}$ pellets and oils were used in $\mathrm{NaCl}$ cells for recording their spectra. ${ }^{1} \mathrm{HNMR}$ spectra were recorded on an NMR Bruker apparatus at $300 \mathrm{MHz}$ and Varian $400 \mathrm{MHz}$ INOVA instrument. ${ }^{13} \mathrm{C}$ NMR spectra were recorded on NMR Bruker apparatus at $75 \mathrm{MHz}$ and Varian $100 \mathrm{MHz}$ INOVA instrument. Chemical shifts are quoted in parts per million from $\mathrm{SiMe}_{4}$ or residual solvent proton signals and coupling constants $(J)$ given in Hertz. Multiplicities are abbreviated as b (broad), s (singlet), d (doublet), t (triplet), q (quartet), m (multiplet), or combinations thereof. Positive ion Matrix Assisted Laser Desorption Ionization Time-of-Flight (MALDI-TOF) mass spectra were recorded using an HP-MALDI instrument using gentisic acid as matrix material. Optical rotations were measured on an ATAGO, AP-100 Automatic polarimeter. Single crystal Xray diffraction data were collected on a Bruker Smart APEX II, CCD detector diffractometer [21]. Data reductions were performed using the SAINT program. The structures were solved by direct methods [22] and refined by full-matrix least squares on F2 by using the SHELXTL-PC package [23]. The figures were plotted with the aid of ORTEP program [24].

2.1. General Procedure for the Synthesis of N-Linked Glycopyranosides $(\mathbf{5 a}-\boldsymbol{e})$. In a round bottom flask $(100 \mathrm{~mL})$, monoester 1 ( $0.61 \mathrm{~g}, 3 \mathrm{mmol})$, EDC $(0.74 \mathrm{~g}, 3 \mathrm{mmol} \times 1.3$ eq.), and catalytic amount of DMAP were placed under nitrogen. $\mathrm{CH}_{2} \mathrm{Cl}_{2}(30 \mathrm{~mL})$ was added as a solvent. After $30 \mathrm{~min}$ glycopyranosyl amine $\mathbf{4 a}-\mathbf{e}(3 \mathrm{mmol})$ was added and the mixture was stirred for $18 \mathrm{~h}$. The byproduct urea was removed by extraction of the reaction mixture with ethyl acetate or chloroform and water $(30 \mathrm{~mL} \times 2)$. The crude product was purified by column chromatography using ethyl acetate : hexane $(3: 7)$ as eluent.

2.2. (2R,3R,5R,6R)-2-(Acetoxymethyl)-6-((4R,5R)-5-(methoxycarbonyl)-2,2-dimethyl-1,3-dioxolane-4-carboxamido)tetrahydro-2H-pyran-3,4,5-triyl Triacetate 5a. Yield: 72\%. Colorless oil $[\alpha]_{\mathrm{D}}^{25}=12.5$. (IR $\left.v \mathrm{~cm}^{-1}\right): 3347(\mathrm{NH}), 2955(\mathrm{CH})$, $1742\left(\mathrm{COOCH}_{3}\right), 1701$ (CONH), 1299 (C-O-C). ${ }^{1} \mathrm{HNMR}$ $\left(400 \mathrm{MHz} \mathrm{CDCl}_{3}\right): \delta(\mathrm{ppm}): 7.18(\mathrm{~d}, J=9.3 \mathrm{~Hz}, \mathrm{NH}), 5.23$, 5.18, 5.05, 4.96 (pseudo t, $J \sim 9.2 \mathrm{~Hz}$ in each, $\mathrm{CH}$ ), 4.65 (d, $J=5.4 \mathrm{~Hz}, \mathrm{CH}), 4.59(\mathrm{~d}, J=5.4 \mathrm{~Hz}, \mathrm{CH}), 4.30(\mathrm{dd}, J=12.5$, $3.6 \mathrm{~Hz}, \mathrm{CH}), 4.21$ (ddd, $J=10.4,3.6,2.1 \mathrm{~Hz}, \mathrm{CH}), 3.95$ (dd, $J=$ 12.5, $2.1 \mathrm{~Hz}, \mathrm{CH}), 3.75\left(\mathrm{~s}, \mathrm{OCH}_{3}\right), 1.94,1.92,1.91,1.89\left(\mathrm{~s}, \mathrm{CH}_{3}\right)$, $1.56\left(\mathrm{~s}, \mathrm{CH}_{3}\right), 1.50\left(\mathrm{~s}, \mathrm{CH}_{3}\right) .{ }^{13} \mathrm{C} \mathrm{NMR}\left(100 \mathrm{MHz}, \mathrm{CDCl}_{3}\right): \delta$ (ppm): $171.2(\mathrm{CONH}), 170.7\left(\mathrm{COOCH}_{3}\right), 170.0,169.9,169.5$, 169.2 (CO), 113.3 (qt C), $81.8(\mathrm{CH}), 76.3(\mathrm{CH}), 75.2(\mathrm{CH}), 73.3$, 72.5, 70.0, $67.8(\mathrm{CH}), 61.2(\mathrm{CH}), 52.4\left(\mathrm{OCH}_{3}\right), 25.9,\left(\mathrm{CH}_{3}\right)$, $25.2\left(\mathrm{CH}_{3}\right), 20.2,20.1(3),\left(\mathrm{CH}_{3}\right)$. HRMS-ESI for $\mathrm{C}_{22} \mathrm{H}_{31} \mathrm{NO}_{14}$ $\mathrm{Na}:[\mathrm{M}+\mathrm{Na}]^{+}$calcd: 556.1745, found: 556.1621. Anal. Calc. For $\mathrm{C}_{22} \mathrm{H}_{31} \mathrm{NO}_{14}$ : C, 49.53; $\mathrm{H}, 5.86 ; \mathrm{N}, 2.63 ; \mathrm{O}, 41.99$ Found C, 49.43; H, 5.56; N, 2.78; O, 42.10 .

2.3. (2R,3R,5R,6R)-2-(Acetoxymethyl)-6-((4R,5R)-5-(methoxycarbonyl)-2,2-dimethyl-1,3-dioxolane-4-carboxamido)tetrahydro-2H-pyran-3,4,5-triyl Triacetate 5b. Yield: 69\%. Colorless oil $[\alpha]_{\mathrm{D}}^{25}=13.3$. (IR $\left.v \mathrm{~cm}^{-1}\right)$ : $3337(\mathrm{NH}), 2925(\mathrm{CH})$, $1732\left(\mathrm{COOCH}_{3}\right), 1703(\mathrm{CONH}), 1292$ (C-O-C). ${ }^{1} \mathrm{HNMR}$ $\left(400 \mathrm{MHz}_{\mathrm{CDCl}}\right): \delta(\mathrm{ppm}): 7.47(\mathrm{~d}, J=9.3 \mathrm{~Hz}, \mathrm{NH}), 5.34$, 5.31, 5.24 (pseudo t, $J=10.0, \mathrm{~Hz}$ in each, $\mathrm{CH}$ ), 4.95 (t, $J=$ $3.9 \mathrm{~Hz}, \mathrm{CH}), 4.93(\mathrm{~d}, J=5.5 \mathrm{~Hz}, \mathrm{CH}), 4.80(\mathrm{~d}, J=5.5 \mathrm{~Hz}$, $\mathrm{CH}), 4.28$ (dd, $J=12.4,3.5 \mathrm{~Hz}, \mathrm{CH}), 4.10$ (ddd, $J=10.3,3.6$, $2.1 \mathrm{~Hz}, \mathrm{CH}), 3.95(\mathrm{dd}, J=12.4,3.5 \mathrm{~Hz}, \mathrm{CH}), 3.77\left(\mathrm{~s}, \mathrm{OCH}_{3}\right)$, 2.34, 2.23, 2.13, $1.99\left(\mathrm{~s}, \mathrm{CH}_{3}\right), 1.52\left(\mathrm{~s}, \mathrm{CH}_{3}\right), 1.46\left(\mathrm{~s}, \mathrm{CH}_{3}\right)$. ${ }^{13} \mathrm{C} \mathrm{NMR}\left(100 \mathrm{MHz}, \mathrm{CDCl}_{3}\right): \delta$ (ppm): $172.2(\mathrm{CONH}), 170.9$ $\left(\mathrm{COOCH}_{3}\right), 170.1,169.6,169.3,169.1$ (CO), 114.3 (qt C), 81.4 $(\mathrm{CH}), 76.5(\mathrm{CH}), 75.1(\mathrm{CH}), 73.1,72.3,70.1,67.9(\mathrm{CH}), 61.8$ $(\mathrm{CH}), 52.9\left(\mathrm{OCH}_{3}\right), 25.5\left(\mathrm{CH}_{3}\right), 25.1\left(\mathrm{CH}_{3}\right), 20.1,20.0$ (3) $\left(\mathrm{CH}_{3}\right)$. HRMS-ESI for $\mathrm{C}_{22} \mathrm{H}_{31} \mathrm{NO}_{14} \mathrm{Na}:[\mathrm{M}+\mathrm{Na}]^{+}$calcd: 556.1745, found: 556.1627. Anal. Calc. For $\mathrm{C}_{22} \mathrm{H}_{31} \mathrm{NO}_{14}$ : C, 
49.53; H, 5.86; N, 2.63; O, 41.99 Found C, 49.43; H, 5.56; N, $2.78 ; \mathrm{O}, 42.10$.

2.4. (2R,3R,5R,6R)-2-(Acetoxymethyl)-6-((4R,5R)-5-(methoxycarbonyl)-2,2-dimethyl-1,3-dioxolane-4-carboxamido)tetrahydro-2H-pyran-3,4,5-triyl Triacetate 5c. Yield: 65\%. Colorless oil $[\alpha]_{\mathrm{D}}^{25}=27.1$. (IR $\left.v \mathrm{~cm}^{-1}\right): 3339(\mathrm{NH}), 2928(\mathrm{CH})$, $1736\left(\mathrm{COOCH}_{3}\right), 1700(\mathrm{CONH}), 1290$ (C-O-C). ${ }^{1} \mathrm{HNMR}$ $\left(400 \mathrm{MHz}, \mathrm{CDCl}_{3}\right): \delta$ (ppm): $7.37(\mathrm{~d}, J=9.3 \mathrm{~Hz}, \mathrm{NH}), 5.42$, 5.40, 5.36 (pseudo t, $J \sim 6.5 \mathrm{~Hz}$ in each, $\mathrm{CH}$ ), $4.98(\mathrm{t}, J=$ $11.9 \mathrm{~Hz}, \mathrm{CH}), 4.97(\mathrm{~d}, J=5.6 \mathrm{~Hz}, \mathrm{CH}), 4.90(\mathrm{~d}, J=5.6 \mathrm{~Hz}$, $\mathrm{CH}), 4.48$ (dd, $J=12.7,3.4 \mathrm{~Hz}, \mathrm{CH}), 4.12(\mathrm{ddd}, J=10.4,3.6$, $2.1 \mathrm{~Hz}, \mathrm{CH}), 3.92(\mathrm{dd}, J=12.4,3.5 \mathrm{~Hz}, \mathrm{CH}), 3.84\left(\mathrm{~s}, \mathrm{OCH}_{3}\right)$, 2.11, 2.10, 2.09, $1.99\left(\mathrm{~s}, \mathrm{CH}_{3}\right), 1.54\left(\mathrm{~s}, \mathrm{CH}_{3}\right), 1.48\left(\mathrm{~s}, \mathrm{CH}_{3}\right)$. ${ }^{13} \mathrm{C} \mathrm{NMR}\left(100 \mathrm{MHz}, \mathrm{CDCl}_{3}\right): \delta$ (ppm): $171.8(\mathrm{CONH}), 170.2$ $\left(\mathrm{COOCH}_{3}\right), 170.3,169.5,169.4,169.2$ (CO), 114.2 (qt C), 81.5 $(\mathrm{CH}), 76.1(\mathrm{CH}), 75.2(\mathrm{CH}), 73.3,72.2,70.1,67.5(\mathrm{CH}), 61.9$ $(\mathrm{CH}), 52.5\left(\mathrm{OCH}_{3}\right), 26.5\left(\mathrm{CH}_{3}\right), 25.7\left(\mathrm{CH}_{3}\right), 20.4,19.5$ (3) $\left(\mathrm{CH}_{3}\right)$. HRMS-ESI for $\mathrm{C}_{22} \mathrm{H}_{31} \mathrm{NO}_{14} \mathrm{Na}:[\mathrm{M}+\mathrm{Na}]^{+}$calcd: 556.1745, found: 556.1643. Anal. Calc. For $\mathrm{C}_{22} \mathrm{H}_{31} \mathrm{NO}_{14}$ : C, 49.53; H, 5.86; N, 2.63; O, 41.99 Found C, 49.43; H, 5.56; N, 2.78; O, 42.10 .

2.5. (2R,3S,5R,6R)-5-Acetamido-2-(acetoxymethyl)-6-((4R, 5R)-5-(methoxycarbonyl)-2,2-dimethyl-1,3-dioxolane-4-carboxamido)tetrahydro-2H-pyran-3,4-diyl Diacetate 5d. Yield: 67\%. Gel like. $[\alpha]_{\mathrm{D}}^{25}=43.3$. (IR $\left.v \mathrm{~cm}^{-1}\right): 3343(\mathrm{NH}), 2948$ $(\mathrm{CH}), 1746\left(\mathrm{COOCH}_{3}\right), 1710$ (CONH), 1293 (C-O-C). ${ }^{1} \mathrm{HNMR}\left(400 \mathrm{MHz}, \mathrm{CDCl}_{3}\right): \delta(\mathrm{ppm}): 7.69(\mathrm{~d}, J=9.5 \mathrm{~Hz}$, $\mathrm{NH}), 7.57(\mathrm{~d}, J=9.3 \mathrm{~Hz}, \mathrm{NH}), 5.43(\mathrm{t}, J=10.0 \mathrm{~Hz}, 1 \mathrm{H}), 5.41-5.32$ (m, CH), 5.37, 4.99 (pseudo t, $J \sim 10.0 \mathrm{~Hz}$ in each, $\mathrm{CH}$ ), 4.96 $(\mathrm{d}, J=5.5 \mathrm{~Hz}, \mathrm{CH}), 4.94(\mathrm{~d}, J=5.5 \mathrm{~Hz}, \mathrm{CH}), 4.44(\mathrm{dd}, J=12.7$, $3.4 \mathrm{~Hz}, \mathrm{CH}), 4.22(\mathrm{ddd}, J=10.4,3.6,2.1 \mathrm{~Hz}, \mathrm{CH}), 3.91$ (dd, $J=$ $12.4,3.5 \mathrm{~Hz}, \mathrm{CH}), 3.86\left(\mathrm{~s}, \mathrm{OCH}_{3}\right), 2.21,2.20,2.19,2.13\left(\mathrm{~s}, \mathrm{CH}_{3}\right)$, $1.57\left(\mathrm{~s}, \mathrm{CH}_{3}\right), 1.49\left(\mathrm{~s}, \mathrm{CH}_{3}\right) .{ }^{13} \mathrm{C} \mathrm{NMR}\left(100 \mathrm{MHz}, \mathrm{CDCl}_{3}\right): \delta$ (ppm): $172.8(\mathrm{CONH}), 171.2\left(\mathrm{COOCH}_{3}\right), 170.2,169.8,169.5$, 169.1 (CO), 114.1 (qt C), $81.8(\mathrm{CH}), 76.1(\mathrm{CH}), 75.3(\mathrm{CH}), 73.2$, 72.1, 70.0, $67.8(\mathrm{CH}), 61.4(\mathrm{CH}), 52.2\left(\mathrm{OCH}_{3}\right), 26.2\left(\mathrm{CH}_{3}\right), 25.8$ $\left(\mathrm{CH}_{3}\right), 20.3,19.3$ (3) $\left(\mathrm{CH}_{3}\right)$. HRMS-ESI for $\mathrm{C}_{22} \mathrm{H}_{32} \mathrm{~N}_{2} \mathrm{O}_{13} \mathrm{Na}$ : $[\mathrm{M}+\mathrm{Na}]^{+}$calcd: 555.1904, found: 555.1619. Anal. Calc. For $\mathrm{C}_{22} \mathrm{H}_{32} \mathrm{~N}_{2} \mathrm{O}_{13}$ : C, 49.62; H, 6.06; N, 5.26; O, 39.06 Found $\mathrm{C}$, 49.32; H, 6.16; N, 5.21; O, 39.16 .

2.6. (2R,3S,5R,6R)-5-Acetamido-2-(acetoxymethyl)-6-((4R, 5R)-5-(methoxycarbonyl)-2,2-dimethyl-1,3-dioxolane-4-carboxamido)tetrahydro-2H-pyran-3,4-diyl Diacetate 5e. Yield: 68\%. Gel like. $[\alpha]_{\mathrm{D}}^{25}=47.1$. $\left(\mathrm{IR} v \mathrm{~cm}^{-1}\right): 3341(\mathrm{NH}), 2942(\mathrm{CH})$, $1745\left(\mathrm{COOCH}_{3}\right), 1711$ (CONH), 1290 (C-O-C). ${ }^{1} \mathrm{HNMR}$ $\left(400 \mathrm{MHz} \mathrm{CDCl}_{3}\right): \delta(\mathrm{ppm}): 7.67(\mathrm{~d}, J=9.6 \mathrm{~Hz}, \mathrm{NH}), 7.55$ $(\mathrm{d}, J=9.3 \mathrm{~Hz}, \mathrm{NH}), 5.41(\mathrm{t}, J=10.8 \mathrm{~Hz}, \mathrm{CH}), 5.40(\mathrm{~m}, \mathrm{CH})$, $5.38,4.97$ (pseudo t, $J \sim 6.9 \mathrm{~Hz}$ in each, $\mathrm{CH}$ ), $4.93(\mathrm{~d}, J=$ $5.6 \mathrm{~Hz}, \mathrm{CH}), 4.91(\mathrm{~d}, J=5.5 \mathrm{~Hz}, \mathrm{CH}), 4.41(\mathrm{dd}, J=12.7,3.4 \mathrm{~Hz}$, $\mathrm{CH}), 4.21$ (ddd, $J=10.4,3.6,2.1 \mathrm{~Hz}, \mathrm{CH}), 3.90(\mathrm{dd}, J=12.4$, $3.5 \mathrm{~Hz}, \mathrm{CH}), 3.83\left(\mathrm{~s}, \mathrm{OCH}_{3}\right), 2.23,2.22,2.20,2.16\left(\mathrm{~s}, \mathrm{CH}_{3}\right)$, $1.56\left(\mathrm{~s}, \mathrm{CH}_{3}\right), 1.46\left(\mathrm{~s}, \mathrm{CH}_{3}\right) .{ }^{13} \mathrm{C} \mathrm{NMR}\left(100 \mathrm{MHz}, \mathrm{CDCl}_{3}\right): \delta$ (ppm): 172.2 (CONH), $171.3\left(\mathrm{COOCH}_{3}\right), 170.5,169.5,169.2$, 169.1 (CO), 113.4 (qt C), $81.6(\mathrm{CH}), 76.4(\mathrm{CH}), 75.2(\mathrm{CH}), 73.4$,
72.3, 70.1, 67.3, $(\mathrm{CH}), 62.4(\mathrm{CH}), 53.2\left(\mathrm{OCH}_{3}\right), 26.2\left(\mathrm{CH}_{3}\right)$, $25.7\left(\mathrm{CH}_{3}\right), 20.7,19.5(3)\left(\mathrm{CH}_{3}\right)$. HRMS-ESI for $\mathrm{C}_{22} \mathrm{H}_{31} \mathrm{NO}_{14}$ $\mathrm{Na}:[\mathrm{M}+\mathrm{Na}]^{+}$calcd: 555.1904, found: 555.1719. Anal. Calc. For $\mathrm{C}_{22} \mathrm{H}_{32} \mathrm{~N}_{2} \mathrm{O}_{13}$ : C, 49.62; $\mathrm{H}, 6.06 ; \mathrm{N}, 5.26$; O, 39.06 Found C, 49.32; H, 6.16; N, 5.21; O, 39.16 .

2.7. General Procedure for the Synthesis of O-Linked Glycopyranosides $(7 \boldsymbol{a}-\boldsymbol{e})$. Hydrazinium acetate $(1.10 \mathrm{~g}, 12 \mathrm{mmol})$ was added to a stirred solution of anomeric mixture of acetylated monosaccharides 1a-e (3.12 g, $8 \mathrm{mmol})$ in DMF $(40 \mathrm{~mL})$. The reaction mixture was heated at $55^{\circ} \mathrm{C}$ for 30 min under a nitrogen atmosphere. After completion, the reaction mixture was diluted with $\mathrm{H}_{2} \mathrm{O}(100 \mathrm{~mL})$ and extracted with EtOAc $(40 \mathrm{~mL} \times 3)$. The combined organic layers were washed with water and brine $(40 \times 2)$, dried over anhydrous $\mathrm{MgSO}_{4}$. The solvent was removed under reduced pressure and the crude product was used without further purification. To the resulting hemiacetal $(1.04 \mathrm{~g}, 3 \mathrm{mmol})$, monoester $1(0.61 \mathrm{~g}$, $3 \mathrm{mmol})$, EDC ( $0.74 \mathrm{~g}, 3 \mathrm{mmol} \times 1.3 \mathrm{eq}$.), and catalytic amount of DMAP were added under nitrogen with $\mathrm{CH}_{2} \mathrm{Cl}_{2}(30 \mathrm{~mL})$. The reaction mixture was stirred for $18 \mathrm{~h}$; the byproduct urea was removed by extraction of the reaction mixture with ethyl acetate or chloroform and water $(30 \mathrm{~mL} \times 3)$. The crude product was purified by column chromatography using ethyl acetate: n-hexane $(3: 7)$ as eluent.

2.8. (4R,5R)-4-Methyl-5-((2S,3R,5R,6R)-3,4,5-triacetoxy-6(acetoxymethyl)tetrahydro-2H-pyran-2-yl)-2,2-dimethyl-1,3dioxolane-4,5-dicarboxylate 7a. Yield: 72\%. Colorless oil $[\alpha]_{\mathrm{D}}^{25}=26.5$. (IR $\left.v \mathrm{~cm}^{-1}\right): 2991(\mathrm{CH}), 1742(\mathrm{CO}), 1366(\mathrm{C}-\mathrm{O}-$ C). ${ }^{1} \mathrm{HNMR}\left(400 \mathrm{MHz}, \mathrm{CDCl}_{3}\right): \delta(\mathrm{ppm}): 6.45(\mathrm{~d}, J=4.0 \mathrm{~Hz}$, $\left.1 \mathrm{H}, \mathrm{H}-1^{\alpha}\right), 5.56\left(\mathrm{~d}, J=8.0 \mathrm{~Hz}, 1 \mathrm{H}, \mathrm{H}-1^{\beta}\right), 5.48,5.45,4.93$ (pseudo t, $J \sim 9.8 \mathrm{~Hz}$ in each, $\mathrm{CH}), 4.91(\mathrm{~d}, J=6.3 \mathrm{~Hz}, \mathrm{CH})$, $4.88(\mathrm{~d}, J=6.3 \mathrm{~Hz}, \mathrm{CH}), 4.32(\mathrm{dd}, J=12.5,3.6 \mathrm{~Hz}, \mathrm{CH}), 4.12$ (ddd, $J=10.4,3.6,2.1 \mathrm{~Hz}, \mathrm{CH}), 3.93(\mathrm{dd}, J=12.5,2.1 \mathrm{~Hz}, \mathrm{CH})$, $3.86\left(\mathrm{~s}, \mathrm{OCH}_{3}\right), 2.19,2.17,2.12,2.04\left(\mathrm{~s}, \mathrm{CH}_{3}\right), 1.55\left(\mathrm{~s}, \mathrm{CH}_{3}\right)$, $1.46\left(\mathrm{~s}, \mathrm{CH}_{3}\right) .{ }^{13} \mathrm{C} \mathrm{NMR}\left(100 \mathrm{MHz}, \mathrm{CDCl}_{3}\right): \delta(\mathrm{ppm}): 172.6$ $\left(\mathrm{COOCH}_{3}\right), 171.2,169.5,169.3,169.0$ (CO), 113.4 (qt C), 92.3 $(\mathrm{CH}), 92.1(\mathrm{CH}), 76.3(\mathrm{CH}), 75.4(\mathrm{CH}), 74.2,73.3,72.1,70.3$ $(\mathrm{CH}), 56.6(\mathrm{CH}), 53.4\left(\mathrm{OCH}_{3}\right), 26.6\left(\mathrm{CH}_{3}\right), 25.9\left(\mathrm{CH}_{3}\right), 20.3$ (2), 19.8, $19.3\left(\mathrm{CH}_{3}\right)$. HRMS-ESI for $\mathrm{C}_{22} \mathrm{H}_{30} \mathrm{O}_{15} \mathrm{Na}:[\mathrm{M}+\mathrm{Na}]^{+}$ calcd: 557.1585, found: 557.1452. Anal. Calc. For $\mathrm{C}_{22} \mathrm{H}_{30} \mathrm{O}_{15}: \mathrm{C}$, 49.44; H, 5.66; O, 44.90 Found C, 49.39; H, 5.70; O, 44.81.

2.9. (4R,5R)-4-Methyl-5-((2S,3R,5R,6R)-3,4,5-triacetoxy-6(acetoxymethyl)tetrahydro-2H-pyran-2-yl)-2,2-dimethyl-1,3dioxolane-4,5-dicarboxylate 7b. Yield: 74\%. Colorless gel $[\alpha]_{\mathrm{D}}^{25}=21.6$. (IR $\left.v \mathrm{~cm}^{-1}\right): 2993(\mathrm{CH}), 1744(\mathrm{CO}), 1361(\mathrm{C}-\mathrm{O}-$ C). ${ }^{1} \mathrm{HNMR}\left(400 \mathrm{MHz}, \mathrm{CDCl}_{3}\right): \delta(\mathrm{ppm}): 6.47(\mathrm{~d}, J=3.9 \mathrm{~Hz}$, $\left.1 \mathrm{H}, \mathrm{H}-1^{\alpha}\right), 5.53\left(\mathrm{~d}, J=8.3 \mathrm{~Hz}, 1 \mathrm{H}, \mathrm{H}-1^{\beta}\right.$ ), 5.47, 4.93 (pseudo t, $J \sim 6.9 \mathrm{~Hz}$ in each, $\mathrm{CH}), 5.50(\mathrm{t}, J=8.9 \mathrm{~Hz}, \mathrm{CH}), 4.94(\mathrm{~d}$, $J=6.3 \mathrm{~Hz}, \mathrm{CH}), 4.88(\mathrm{~d}, J=6.3 \mathrm{~Hz}, \mathrm{CH}), 4.27(\mathrm{dd}, J=12.5$, $3.6 \mathrm{~Hz}, \mathrm{CH}), 4.14$ (ddd, $J=10.4,3.6,2.1 \mathrm{~Hz}, \mathrm{CH}), 3.96$ (dd, $J=$ 12.5, 2.1 Hz, CH), $3.86\left(\mathrm{~s}, \mathrm{OCH}_{3}\right), 2.19,2.17,2.12,2.04\left(\mathrm{~s}, \mathrm{CH}_{3}\right)$, $1.55\left(\mathrm{~s}, \mathrm{CH}_{3}\right), 1.45\left(\mathrm{~s}, \mathrm{CH}_{3}\right) .{ }^{13} \mathrm{C} \mathrm{NMR}\left(100 \mathrm{MHz}, \mathrm{CDCl}_{3}\right): \delta$ (ppm): $172.3\left(\mathrm{COOCH}_{3}\right), 171.7,169.4,169.3,169.1(\mathrm{CO}), 113.3$ (qt C), $92.7(\mathrm{CH}), 92.4(\mathrm{CH}), 76.2(\mathrm{CH}), 75.6(\mathrm{CH}), 74.4,73.5$, 
72.2, 70.2, $(\mathrm{CH}), 56.5(\mathrm{CH}), 53.2\left(\mathrm{OCH}_{3}\right), 25.6\left(\mathrm{CH}_{3}\right), 24.9$ $\left(\mathrm{CH}_{3}\right), 20.6(2)$, 19.7, $19.5\left(\mathrm{CH}_{3}\right)$. HRMS-ESI for $\mathrm{C}_{22} \mathrm{H}_{30} \mathrm{O}_{15}$ $\mathrm{Na}:[\mathrm{M}+\mathrm{Na}]^{+}$calcd: 557.1585 , found: 557.1466. Anal. Calc. For $\mathrm{C}_{22} \mathrm{H}_{30} \mathrm{O}_{15}$ : C, 49.44; $\mathrm{H}, 5.66 ; \mathrm{O}, 44.90$ Found C, 49.39; $\mathrm{H}, 5.70$; O, 44.81.

2.10. (4R,5R)-4-Methyl-5-((2R,3R,5R,6R)-3,4,5-triacetoxy-6(acetoxymethyl)tetrahydro-2H-pyran-2-yl)-2,2-dimethyl-1,3dioxolane-4,5-dicarboxylate $7 c$. Yield: 70\%. White foam m.p $=151-153^{\circ} \mathrm{C} .[\alpha]_{\mathrm{D}}^{25}=17.3$. $\left(\operatorname{IR} v \mathrm{~cm}^{-1}\right): 2995(\mathrm{CH}), 1745(\mathrm{CO})$, 1336 (C-O-C). ${ }^{1} \mathrm{HNMR}\left(400 \mathrm{MHz}, \mathrm{CDCl}_{3}\right.$ ): $\delta$ (ppm): 6.42 $\left(\mathrm{d}, J=3.7 \mathrm{~Hz}, 1 \mathrm{H}, \mathrm{H}-1^{\alpha}\right), 5.51\left(\mathrm{~d}, J=4.0 \mathrm{~Hz}, 1 \mathrm{H}, \mathrm{H}-1^{\beta}\right), 5.46$, 5.43 (pseudo t, $J \sim 5.6 \mathrm{~Hz}$ in each, $\mathrm{CH}$ ), $4.96(\mathrm{t}, J=9.8 \mathrm{~Hz}$, $\mathrm{CH}), 4.93(\mathrm{~d}, J=5.3 \mathrm{~Hz}, \mathrm{CH}), 4.89$ (d, $J=5.3 \mathrm{~Hz}, \mathrm{CH}), 4.26$ $(\mathrm{dd}, J=12.5,3.6 \mathrm{~Hz}, \mathrm{CH}), 4.13(\mathrm{ddd}, J=10.4,3.6,2.1 \mathrm{~Hz}$, $\mathrm{CH}), 3.93(\mathrm{dd}, J=12.5,2.1 \mathrm{~Hz}, \mathrm{CH}), 3.76\left(\mathrm{~s}, \mathrm{OCH}_{3}\right), 2.15$, 2.14, 2.12, $2.11\left(\mathrm{~s}, \mathrm{CH}_{3}\right), 1.56\left(\mathrm{~s}, \mathrm{CH}_{3}\right), 1.46\left(\mathrm{~s}, \mathrm{CH}_{3}\right) .{ }^{13} \mathrm{C} \mathrm{NMR}$ $\left(100 \mathrm{MHz}, \mathrm{CDCl}_{3}\right): \delta$ (ppm): $171.3\left(\mathrm{COOCH}_{3}, 170.7,169.6\right.$, 169.3, 169.1 (CO), 113.4 (qt C), $92.4(\mathrm{CH}), 92.1(\mathrm{CH}), 76.1$ $(\mathrm{CH}), 75.6(\mathrm{CH}), 74.2,73.2,72.1,70.5(\mathrm{CH}), 56.7(\mathrm{CH}), 53.3$ $\left(\mathrm{OCH}_{3}\right), 26.6\left(\mathrm{CH}_{3}\right), 25.8\left(\mathrm{CH}_{3}\right), 20.2(2), 19.8,19.4\left(\mathrm{CH}_{3}\right)$. HRMS-ESI for $\mathrm{C}_{22} \mathrm{H}_{30} \mathrm{O}_{15} \mathrm{Na}:[\mathrm{M}+\mathrm{Na}]^{+}$calcd: 557.1585, found: 557.1475. Anal. Calc. For $\mathrm{C}_{22} \mathrm{H}_{30} \mathrm{O}_{15}$ : C, 49.44; H, 5.66; O, 44.90 Found C, 49.39; H, 5.70; O, 44.88.

2.11. (4R,5R)-4-((2S,3R,5S,6R)-3-Acetamido-4,5-diacetoxy-6(acetoxymethyl)tetrahydro-2H-pyran-2-yl)-5-methyl-2,2-dimethyl-1,3-dioxolane-4,5-dicarboxylate 7d. Yield: 67\%. Colorless oil $[\alpha]_{\mathrm{D}}^{25}=45.0$. (IR $\left.v \mathrm{~cm}^{-1}\right): 3342(\mathrm{NH}), 2981(\mathrm{CH}), 1739$ (CO), 1360 (C-O-C). ${ }^{1} \mathrm{HNMR}\left(400 \mathrm{MHz}, \mathrm{CDCl}_{3}\right): \delta(\mathrm{ppm})$ : $7.87(\mathrm{~d}, J=9.5 \mathrm{~Hz}, \mathrm{NH}), 6.49\left(\mathrm{~d}, J=3.7 \mathrm{~Hz}, 1 \mathrm{H}, \mathrm{H}-1^{\alpha}\right), 5.57$ $\left(\mathrm{d}, J=8.3 \mathrm{~Hz}, 1 \mathrm{H}, \mathrm{H}-1^{\beta}\right), 5.46(\mathrm{~m}, \mathrm{CH}) 5.43,4.96$ (pseudo $\mathrm{t}$, $J \sim 7.4 \mathrm{~Hz}$ in each, $\mathrm{CH}), 4.94(\mathrm{~d}, J=6.3 \mathrm{~Hz}, \mathrm{CH}), 4.83(\mathrm{~d}, J=$ $6.3 \mathrm{~Hz}, \mathrm{CH}), 4.37$ (dd, $J=12.5,3.6 \mathrm{~Hz}, \mathrm{CH}), 4.23$ (ddd, $J=10.4$, 3.6, 2.1 Hz, CH), $3.93(\mathrm{dd}, J=12.5,2.1 \mathrm{~Hz}, \mathrm{CH}), 3.87\left(\mathrm{~s}, \mathrm{OCH}_{3}\right)$, 2.13, 2.11, 2.10, $2.04\left(\mathrm{~s}, \mathrm{CH}_{3}\right), 1.57\left(\mathrm{~s}, \mathrm{CH}_{3}\right), 1.49\left(\mathrm{~s}, \mathrm{CH}_{3}\right)$. ${ }^{13} \mathrm{C} \mathrm{NMR}\left(100 \mathrm{MHz}, \mathrm{CDCl}_{3}\right): \delta(\mathrm{ppm}): 171.6\left(\mathrm{COOCH}_{3}\right)$, 170.3, 169.3, 169.2, 169.0 (CO), 113.6 (qt C), $92.6(\mathrm{CH}), 92.2$ $(\mathrm{CH}), 76.2(\mathrm{CH}), 75.1(\mathrm{CH}), 74.5,73.3,72.6,70.1(\mathrm{CH}), 57.9$ $(\mathrm{CH}), 53.5\left(\mathrm{OCH}_{3}\right), 26.4\left(\mathrm{CH}_{3}\right), 25.6\left(\mathrm{CH}_{3}\right), 20.1(2), 19.5$, 19.2, $\left(\mathrm{CH}_{3}\right)$. HRMS-ESI for $\mathrm{C}_{22} \mathrm{H}_{31} \mathrm{NO}_{14} \mathrm{Na}:[\mathrm{M}+\mathrm{Na}]^{+}$calcd: 556.1745, found: 556.1614. Anal. Calc. For $\mathrm{C}_{22} \mathrm{H}_{31} \mathrm{NO}_{14}$ : C, 49.53; H, 5.86; N, 2.63; O, 41.99 Found C, 49.55; H, 5.76; N, 2.60; O, 41.90 .

2.12. (4R,5R)-4-((2S,3R,5S,6R)-3-Acetamido-4,5-diacetoxy-6(acetoxymethyl)tetrahydro-2H-pyran-2-yl)-5-methyl-2,2-dimethyl-1,3-dioxolane-4,5-dicarboxylate 7e. Yield: 63\%. Colorless oil $[\alpha]_{\mathrm{D}}^{25}=33.3$. (IR $\left.v \mathrm{~cm}^{-1}\right): 3348(\mathrm{NH}), 2990(\mathrm{CH}), 1741$ (CO), 1356 (C-O-C). ${ }^{1} \mathrm{HNMR}\left(400 \mathrm{MHz}, \mathrm{CDCl}_{3}\right.$ ): $\delta$ (ppm): $7.86(\mathrm{~d}, J=9.7 \mathrm{~Hz}, \mathrm{NH}), 6.52\left(\mathrm{~d}, J=3.9 \mathrm{~Hz}, 1 \mathrm{H}, \mathrm{H}-1^{\alpha}\right), 5.67$ $\left(\mathrm{d}, J=8.7 \mathrm{~Hz}, 1 \mathrm{H}, \mathrm{H}-1^{\beta}\right.$ ), $5.46(\mathrm{~m}, \mathrm{CH}), 5.43,4.96$ (pseudo t, $J \sim 6.0 \mathrm{~Hz}$ in each, CH), $4.93(\mathrm{~d}, J=5.4 \mathrm{~Hz}, \mathrm{CH}), 4.82$ $(\mathrm{d}, J=5.3 \mathrm{~Hz}, \mathrm{CH}), 4.38(\mathrm{dd}, J=12.5,3.6 \mathrm{~Hz}, \mathrm{CH}), 4.33$ (ddd, $J=10.4,3.6,2.1 \mathrm{~Hz}, \mathrm{CH}), 3.93(\mathrm{dd}, J=12.5,2.1 \mathrm{~Hz}$, $\mathrm{CH}), 3.85\left(\mathrm{~s}, \mathrm{OCH}_{3}\right), 2.14,2.12,2.10,2.06\left(\mathrm{~s}, \mathrm{CH}_{3}\right), 1.56(\mathrm{~s}$, $\left.\mathrm{CH}_{3}\right), 1.46\left(\mathrm{~s}, \mathrm{CH}_{3}\right) .{ }^{13} \mathrm{C} \mathrm{NMR}\left(100 \mathrm{MHz}, \mathrm{CDCl}_{3}\right): \delta(\mathrm{ppm})$ :
$171.4\left(\mathrm{COOCH}_{3}\right), 170.3,169.5,169.4,169.2(\mathrm{CO}), 114.4$ (qt C), 93.4 (CH), $92.7(\mathrm{CH}), 76.3(\mathrm{CH}), 75.2(\mathrm{CH}), 74.5,73.4,72.6$, $70.1(\mathrm{CH}), 58.7(\mathrm{CH}), 53.5\left(\mathrm{OCH}_{3}\right), 26.6\left(\mathrm{CH}_{3}\right), 25.6\left(\mathrm{CH}_{3}\right)$, 20.1 (2), 19.4, $19.1\left(\mathrm{CH}_{3}\right)$. HRMS-ESI for $\mathrm{C}_{22} \mathrm{H}_{31} \mathrm{NO}_{14} \mathrm{Na}$ : $[\mathrm{M}+\mathrm{Na}]^{+}$calcd: 556.1745, found: 556.1616. Anal. Calc. For $\mathrm{C}_{22} \mathrm{H}_{31} \mathrm{NO}_{14}$ : C, 49.53; H, 5.86; N, 2.63; O, 41.99 Found C, $49.55 ; \mathrm{H}, 5.81 ; \mathrm{N}, 2.60 ; \mathrm{O}, 41.91$.

\section{Results and Discussion}

As outlined in synthetic Schemes 1 and 2, our proposed strategy was to transform five different glycopyranoses to glycopyranosyl amines $\mathbf{4 a - e}$ which would serve as nucleophiles. In sugars, the anomeric position is comparatively more reactive due to the presence of the endocyclic oxygen atom. Owing to its higher reactivity, microwave assisted Kochetkov amination was tried. The Kochetkov amination is used to introduce amino functionality at the anomeric position in unprotected sugars [25]. However, when glucose was reacted under microwave with Kochetkov reagents, that is, ammonium carbonate in DMSO, a mixture of amino and untreated glucose was obtained after prolonged lipophilization. In the case of glucosamine and galactosamine hydrochlorides, which already contain amino functionality, to ensure chemoselectivity in coupling with tartaric acid, a relative long route was adopted involving protecting the entire hydroxyl and amino functionalities on these sugars. Thus per acetylation [26], followed by anomeric bromination [27], azide formation [28] and reduction of azides afforded the target acetylated glycopyranosyl amines $\mathbf{4 a - e}$.

Following the same coupling procedure with increased time (Table 2), O-linked glycopyranosides $7 \mathbf{a}-\mathbf{e}$ were also prepared in $63-74 \%$ yields, starting from acetylated monosaccharides la-e, Scheme 3.

It was observed that during per acetylation, a mixture of both $\alpha$ and $\beta$ anomers is formed in a $3: 1$ ratio. In the bromination step, the thermodynamically more stable $\alpha$ anomer was obtained exclusively. In the resultant bromo analogue when left for longer time (two days), slight decomposition was observed. Therefore the product was used in the next step immediately. The reaction of bromide $\mathbf{3 a}$ with sodium azide in DMF proceeded in low yield; however under sonication, the azide analogue was produced in excellent yield. The substitution involves inversion of configuration at the anomeric site and thus the $\alpha$-glycopyranosyl bromide gave the corresponding $\beta$-glycopyranosyl azide. The azide intermediates were reduced immediately under catalytic hydrogenation in the next step. The hydrogenation reaction furnished the desired amines in quantitative yield, which were stable when completely dried under vacuum. Once a series of glycopyranosyl amines $4 \mathbf{a}-\mathbf{e}$ were generated, the next step was to synthesize the monoester 1 starting from commercially available L-tartaric acid. Both the hydroxyl and carboxyl groups were protected followed by partial hydrolysis with one equivalent of lithium hydroxide; however the yield was variable. By the use of a stronger base sodium hydroxide, the yield was improved. It is important to mention that the formation of monoester $\mathbf{1}$ from the diester does not depend 


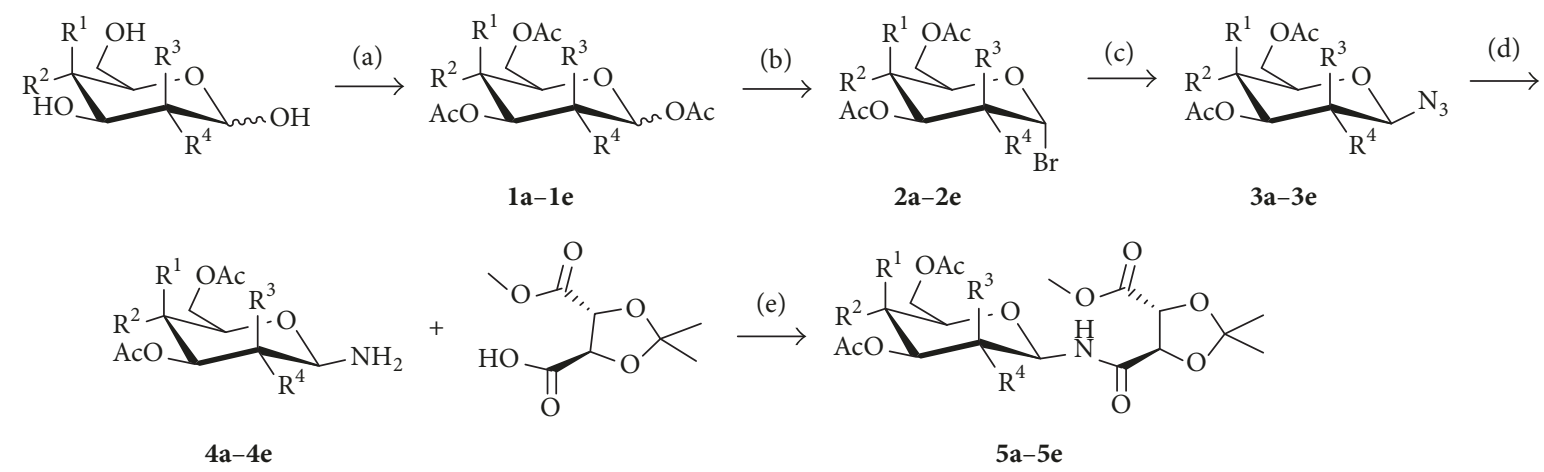
(a) D-Glucose $\mathrm{R}^{1}, \mathrm{R}^{3}=\mathrm{H} ; \mathrm{R}^{2}, \mathrm{R}^{4}=\mathrm{OH}$
(d) D-Glucosamine $\cdot \mathrm{HCl} \quad \mathrm{R}^{1}, \mathrm{R}^{3}=\mathrm{H} ; \mathrm{R}^{2}=\mathrm{OH} ; \mathrm{R}^{4}=\mathrm{NH}_{2} \cdot \mathrm{HCl}$
(b) D-Galactose $\mathrm{R}^{1}, \mathrm{R}^{4}=\mathrm{OH} ; \mathrm{R}^{2}, \mathrm{R}^{3}=\mathrm{H}$
(c) D-Mannose $\mathrm{R}^{1}, \mathrm{R}^{4}=\mathrm{H} ; \mathrm{R}^{2}, \mathrm{R}^{3}=\mathrm{OH}$
(e) D-Galactosamine $\cdot \mathrm{HCl} \quad \mathrm{R}^{1}=\mathrm{OH} ; \mathrm{R}^{2}, \mathrm{R}^{3}=\mathrm{H} ; \mathrm{R}^{4}=\mathrm{NH}_{2} \cdot \mathrm{HCl}$

Scheme 1: Reagents and conditions: (a) $\mathrm{Ac}_{2} \mathrm{O}$, pyridine, cat. DMAP, $\mathrm{N}_{2}$, r.t., overnight; (b) $\mathrm{HBr} / \mathrm{AcOH}(30 \%), \mathrm{CH}_{2} \mathrm{Cl}_{2}, \mathrm{~N}_{2}$, r.t., 2 h; (c) $\mathrm{NaN}_{3}$, DMF, sonication, r.t., $15 \mathrm{~min}$; (d) $\mathrm{Pd} / \mathrm{C}(10 \%), \mathrm{H}_{2}, \mathrm{MeOH}, 30 \mathrm{~min}$; (e) $\mathrm{EDC}, \mathrm{CH}_{2} \mathrm{Cl}_{2}$, cat. DMAP, $\mathrm{N}_{2}$, r.t., 18 h.<smiles>COC(=O)[C@H]1OC(C)(C)O[C@H]1C(=O)OC</smiles>

(1)

Scheme 2: Reagents and conditions: (a) $\mathrm{MeOH}, \mathrm{H}^{+}$, reflux, 2 h, 2-methoxypropene, CSA, DMF, $\mathrm{N}_{2}$, r.t., overnight; (b) $\mathrm{NaOH}(1 \mathrm{eq}), \mathrm{MeOH}$, r.t., 2 h.

on which ester group of the two is cleaved as both groups are homotopic and therefore monohydrolysis of any of these groups will lead to identical molecules. The same strategy was then used for all of the compounds in the series.

With glycopyranosyl amines and monoester in hand, it was decided to use coupling reagents to form peptides $5 \mathbf{a}-\mathbf{e}$. Different coupling conditions were tried to generate the target amides, Table 1. DCC in the presence of a DMAP catalyst furnished the target amide in low yield. EDC when used in 1.3 equivalents for $12 \mathrm{~h}$ afforded the amides in good yield and the reaction was reproducible. Once coupling conditions were optimized, the same coupling conditions were used for the rest of the series to furnish the respective amides, Table 1.

The coupling reaction was high yielding and the compounds were purified by column chromatography. IR spectral data of the compounds $5 \mathbf{a}-\mathbf{e}$ exhibited the appearance of characteristic $(\mathrm{NH})$ stretching bands in the range of $3347-3331 \mathrm{~cm}^{-1}$ and disappearance of $\mathrm{NH}_{2}$ stretching. Two $\mathrm{C}=\mathrm{O}$ stretching bands ranging from 1742 to 1736 and 1701 to $1692 \mathrm{~cm}^{-1}$ were assigned to ester and amide, respectively. ${ }^{1}$ HNMR spectral data shows characteristic doublets for the NH protons in the range of $7.69-7.18 \mathrm{ppm}$ with a coupling constant of $9.6-9.3 \mathrm{~Hz}$. The anomeric protons appeared as pseudotriplets in the range of $5.42-5.36 \mathrm{ppm}$ with coupling constant of $12.2-6.5 \mathrm{~Hz}$ which confirms the formation of the $\beta$-anomer. In ${ }^{13} \mathrm{C} \mathrm{NMR}$ spectra, peaks ranging from $172.8-171.2 \mathrm{ppm}$ were assigned to $\mathrm{C}=\mathrm{O}$ (amide) and 170.9-170.2 ppm to $\mathrm{C}=\mathrm{O}$ (ester), respectively. Elemental analysis of the glycopyranosyl amides $5 \mathbf{a}-\mathbf{e}$ confirmed the structures of the compounds. The exact mass of the compounds was confirmed by HRMS-ESI.

The anomeric acetyl group was hydrolyzed selectively using hydrazinium acetate, in DMF [29-31]; the resulting hemiacetal was washed with water and brine and used without further purification. To the crude hemiacetal, monoester was added using EDC as a coupling agent. When compound 6a was coupled with monoester 1 using 1.3 eq. EDC, DMAP with increased reaction time afforded compound $7 \mathbf{a}$ in $72 \%$ yield. Once the reaction conditions were optimized, the same conditions were used for the rest of the series to furnish the respective esters, Table 2 .

The synthesized compounds were purified by column chromatography and characterized by spectroscopic techniques. IR spectral data of the compounds $7 \mathbf{a}-\mathbf{e}$ showed characteristic $(\mathrm{C}=\mathrm{O})$ stretching bands ranging from 1745 to $1739 \mathrm{~cm}^{-1}$ in addition to C-O-C stretching in 1366-1356. The NH stretching bands 7d-e appeared in $3348-3342 \mathrm{~cm}^{-1}$. ${ }^{1} \mathrm{HNMR}$ spectral data showed doublets $7 \mathbf{d}-\mathbf{e}$, for the $\mathrm{NH}$ protons in the range of 7.87-7.86 ppm with coupling constant of $9.7-9.5 \mathrm{~Hz}$. Both $\alpha$ - and $\beta$-anomers were found to be $1: 3$ except compound $7 \mathrm{c}$ where $\alpha$ and $\beta$ ratio was $1: 1$ as confirmed by ${ }^{1} \mathrm{HNMR}$ spectroscopy. The anomeric protons appeared as doublets in the range of $5.67-5.43 \mathrm{ppm}$ with coupling constant of $8.3-8.0 \mathrm{~Hz}$ for the $\beta$-anomers 


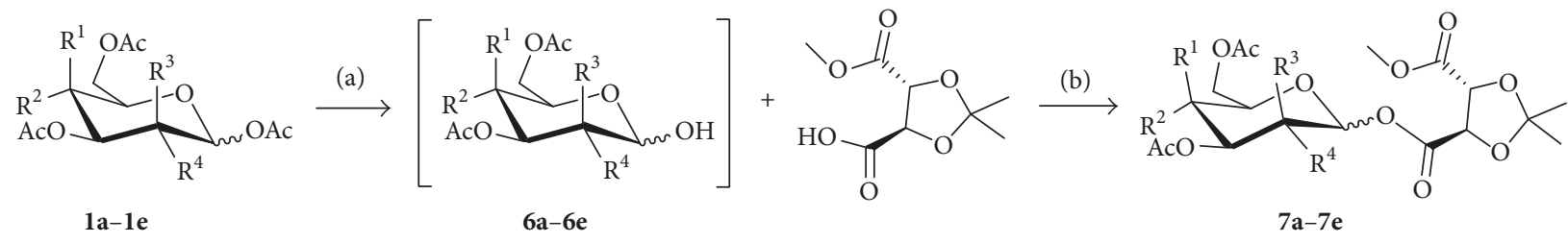

Scheme 3: Reagents and conditions: (a) $\mathrm{N}_{2} \mathrm{H}_{4} / \mathrm{AcOH}$ (1.5 eq.), DMF, $55^{\circ} \mathrm{C}, \mathrm{N}_{2}, 30 \mathrm{~min}$; (b) $\mathrm{EDC}, \mathrm{CH}_{2} \mathrm{Cl}_{2}$, cat. DMAP, $\mathrm{N}_{2}$, rt, 18 h.

TABLE 1: Different coupling condition for amide synthesis.

\begin{tabular}{llccc}
\hline Entry & \multicolumn{2}{c}{ Starting material } & Reagents/conditions & Product (isolated yield\%) \\
\hline 1 & $\mathbf{4 a}$ & $\mathrm{HA}$ & 1.2 eq. $\mathrm{DCC}$, cat. $\mathrm{DMAP}, \mathrm{CH}_{2} \mathrm{Cl}_{2}$, r.t., $8 \mathrm{~h}$ & 46 \\
2 & $\mathbf{4 a}$ & $\mathrm{HA}$ & 1 eq. EDC, cat. $\mathrm{DMAP}, \mathrm{CH}_{2} \mathrm{Cl}_{2}$ r.t., $8 \mathrm{~h}$ & 36 \\
3 & $\mathbf{4 a}$ & $\mathrm{HA}$ & 1.1 eq. EDC, cat. DMAP, $\mathrm{CH}_{2} \mathrm{Cl}_{2}$ r.t., $12 \mathrm{~h}$ & 70 \\
4 & $\mathbf{4 a}$ & $\mathrm{HA}$ & 1.3 eq. EDC, cat. DMAP, $\mathrm{CH}_{2} \mathrm{Cl}_{2}$ r.t., $12 \mathrm{~h}$ & 76 \\
5 & $\mathbf{5 a}$ & $\mathrm{HA}$ & 1.3 eq. EDC, cat. $\mathrm{DMAP}, \mathrm{CH}_{2} \mathrm{Cl}_{2}$ r.t., 12 h & 61 \\
6 & $\mathbf{6 a}$ & $\mathrm{HA}$ & 1.3 eq. EDC, cat. DMAP, $\mathrm{CH}_{2} \mathrm{Cl}_{2}$ r.t., $18 \mathrm{~h}$ & 79 \\
\hline
\end{tabular}

and in 6.52-6.42 ppm with coupling constant of $4.0-3.7 \mathrm{~Hz}$ for the $\alpha$-anomers, respectively. The coupling constant of anomeric hydrogen for mannopyranosyl $7 \mathrm{c}$ was $4.0 \mathrm{~Hz}$ in both the anomers. Finally the synthesis of glycopyranosides was supported by one of the crystal structure for $\alpha$-anomer, $O$-(2,3,4,6-tetra-O-acetyl- $\alpha$-D-mannopyranosyl)(4R,5R)-2,2-dimethyl-1,3-dioxolane-4,5-dicarboxylate 7c by $\mathrm{X}$-ray crystallography (Figure 1).

Crystal system $=$ monoclinic. Torsion angles for compound $7 \mathrm{c}$ are $\mathrm{C} 5-\mathrm{O} 1-\mathrm{C} 1-\mathrm{O} 13=-62.9(2)^{\circ}, \mathrm{C} 5-\mathrm{O} 1-\mathrm{C} 1-\mathrm{C} 2$ $=54.9(2)^{\circ}, \mathrm{C} 15-\mathrm{O} 13-\mathrm{C} 1-\mathrm{O} 1=-76.4(2)(2)^{\circ}, \mathrm{C} 15-\mathrm{O} 13-\mathrm{C} 1-$ $\mathrm{C} 2=160.28(19)^{\circ}, \mathrm{C} 13-\mathrm{O} 8-\mathrm{C} 2-\mathrm{C} 3=-103.8(2)^{\circ}, \mathrm{C} 13-\mathrm{O} 8-$ $\mathrm{C} 2-\mathrm{C} 1=136.00(19)^{\circ}, \mathrm{O} 1-\mathrm{C} 1-\mathrm{C} 2-\mathrm{O} 8=73.3(2)^{\circ}, \mathrm{O} 13-\mathrm{C} 1-$ $\mathrm{C} 2-\mathrm{O} 8=-165.60(16)^{\circ}, \mathrm{O} 1-\mathrm{C} 1-\mathrm{C} 2-\mathrm{C} 3=-46.9(2)^{\circ}$, O13-C1$\mathrm{C} 2-\mathrm{C} 3=74.2(2)^{\circ}, \mathrm{C} 11-\mathrm{O} 6-\mathrm{C} 3-\mathrm{C} 4=-149.8(2)^{\circ}, \mathrm{C} 11-\mathrm{O} 6-$ $\mathrm{C} 3-\mathrm{C} 2=88.7(3)^{\circ}, \mathrm{O} 8-\mathrm{C} 2-\mathrm{C} 3-\mathrm{O} 6=49.8(2)^{\circ}, \mathrm{C} 1-\mathrm{C} 2-\mathrm{C} 3-$ $\mathrm{O} 6=167.17(17)^{\circ}, \mathrm{O} 8-\mathrm{C} 2-\mathrm{C} 3-\mathrm{C} 4=-69.0(2)^{\circ}, \mathrm{C} 1-\mathrm{C} 2-\mathrm{C} 3-$ $\mathrm{C} 4=48.4(3)^{\circ}, \mathrm{C} 9-\mathrm{O} 4-\mathrm{C} 4-\mathrm{C} 3=-119.6(3)^{\circ}, \mathrm{C} 9-\mathrm{O} 4-\mathrm{C} 4-$ $\mathrm{C} 5=123.8(3)^{\circ}, \mathrm{O} 6-\mathrm{C} 3-\mathrm{C} 4-\mathrm{O} 4=67.2(2)^{\circ}, \mathrm{C} 2-\mathrm{C} 3-\mathrm{C} 4-\mathrm{O} 4$ $=-172.34(18)^{\circ}, \mathrm{O} 6-\mathrm{C} 3-\mathrm{C} 4-\mathrm{C} 5=-176.24(17)^{\circ}, \mathrm{C} 2-\mathrm{C} 3-\mathrm{C} 4-$ $\mathrm{C} 5=-55.8(2)^{\circ}, \mathrm{C} 1-\mathrm{O} 1-\mathrm{C} 5-\mathrm{C} 6=176.43(19)^{\circ}, \mathrm{C} 1-\mathrm{O} 1-\mathrm{C} 5-$ $\mathrm{C} 4=-61.4(2)^{\circ}, \mathrm{O} 4-\mathrm{C} 4-\mathrm{C} 5-\mathrm{O} 1=176.08(18)^{\circ}, \mathrm{C} 3-\mathrm{C} 4-\mathrm{C} 5-$ $\mathrm{O} 1=60.3(2)^{\circ}, \mathrm{O} 4-\mathrm{C} 4-\mathrm{C} 5-\mathrm{C} 6=-65.2(3)^{\circ}, \mathrm{C} 3-\mathrm{C} 4-\mathrm{C} 5-\mathrm{C} 6$ $=179.0(2)^{\circ}, \mathrm{C} 7-\mathrm{O} 2-\mathrm{C} 6-\mathrm{C} 5=-153.1(2)^{\circ}, \mathrm{O} 1-\mathrm{C} 5-\mathrm{C} 6-\mathrm{O} 2=$ $-68.2(3)^{\circ}, \mathrm{C} 4-\mathrm{C} 5-\mathrm{C} 6-\mathrm{O} 2=172.1(2)^{\circ}, \mathrm{C} 6-\mathrm{O} 2-\mathrm{C} 7-\mathrm{O} 3=1.9(5)^{\circ}$, $\mathrm{C} 6-\mathrm{O} 2-\mathrm{C} 7-\mathrm{C} 8=-175.2(3)^{\circ}, \mathrm{C} 4-\mathrm{O} 4-\mathrm{C} 9-\mathrm{O} 5=-7.1(6)^{\circ}, \mathrm{C} 4-$ $\mathrm{O} 4-\mathrm{C} 9-\mathrm{C} 10=174.8(3)^{\circ}, \mathrm{C} 3-\mathrm{O} 6-\mathrm{C} 11-\mathrm{O} 7=3.7(4)^{\circ}, \mathrm{C} 3-\mathrm{O} 6-\mathrm{C} 11-$ $\mathrm{C} 12=-175.5(2)^{\circ}, \mathrm{C} 2-\mathrm{O} 8-\mathrm{C} 13-\mathrm{O} 9=6.4(3)^{\circ}, \mathrm{C} 2-\mathrm{O} 8-\mathrm{C} 13-\mathrm{C} 14$ $=-171.9(2)^{\circ}, \mathrm{C} 1-\mathrm{O} 13-\mathrm{C} 15-\mathrm{O} 12=-5.2(4)^{\circ}, \mathrm{C} 1-\mathrm{O} 13-\mathrm{C} 15-\mathrm{C} 16$ $=173.8(2)^{\circ}, \mathrm{C} 19-\mathrm{O} 15-\mathrm{C} 16-\mathrm{C} 15=131.8(4)^{\circ}, \mathrm{C} 19-\mathrm{O} 15-\mathrm{C} 16-\mathrm{C} 17$ $=11.0(5)^{\circ}, \mathrm{O} 12-\mathrm{C} 15-\mathrm{C} 16-\mathrm{O} 15=-7.6(4)^{\circ}, \mathrm{O} 13-\mathrm{C} 15-\mathrm{C} 16-\mathrm{O} 15=$ $173.5(2)^{\circ}, \mathrm{O} 12-\mathrm{C} 15-\mathrm{C} 16-\mathrm{C} 17=108.9(4)^{\circ}, \mathrm{O} 13-\mathrm{C} 15-\mathrm{C} 16-\mathrm{C} 17=$ $-70.1(3)^{\circ}, \mathrm{C} 19-\mathrm{O} 14-\mathrm{C} 17-\mathrm{C} 18=130.6(5)^{\circ}, \mathrm{C} 19-\mathrm{O} 14-\mathrm{C} 17-\mathrm{C} 16=$ $11.5(6)^{\circ}, \mathrm{O} 15-\mathrm{C} 16-\mathrm{C} 17-\mathrm{O} 14=-13.4(5)^{\circ}, \mathrm{C} 15-\mathrm{C} 16-\mathrm{C} 17-\mathrm{O} 14=$ $-133.2(4)^{\circ}, \mathrm{O} 15-\mathrm{C} 16-\mathrm{C} 17-\mathrm{C} 18=-131.8(3)^{\circ}, \mathrm{C} 15-\mathrm{C} 16-\mathrm{C} 17-\mathrm{C} 18$ $=108.4(3)^{\circ}, \mathrm{C} 22-\mathrm{O} 11-\mathrm{C} 18-\mathrm{O} 10=-2.3(9)^{\circ}, \mathrm{C} 22-\mathrm{O} 11-\mathrm{C} 18-\mathrm{C} 17$ $=178.0(4)^{\circ}, \mathrm{O} 14-\mathrm{C} 17-\mathrm{C} 18-\mathrm{O} 10=-31.2(7)^{\circ}, \mathrm{C} 16-\mathrm{C} 17-\mathrm{C} 18-\mathrm{O} 10$ $=82.9(6)^{\circ}, \mathrm{O} 14-\mathrm{C} 17-\mathrm{C} 18-\mathrm{O} 11=148.5(4)^{\circ}, \mathrm{C} 16-\mathrm{C} 17-\mathrm{C} 18-\mathrm{O} 11=$

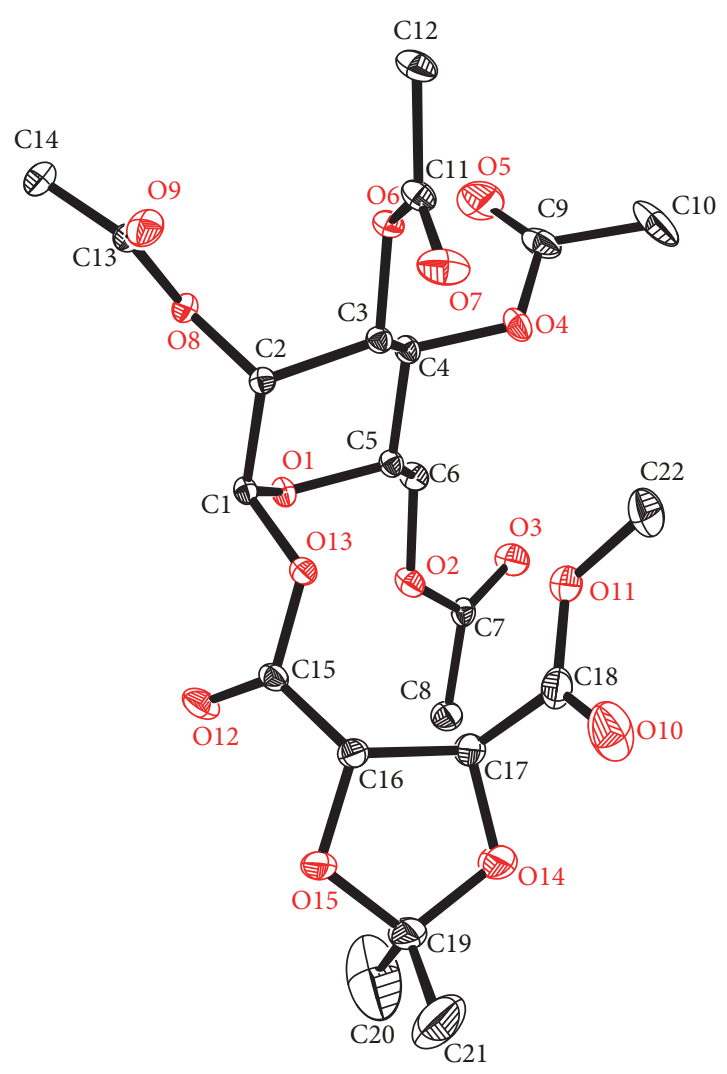

FIGURE 1: Crystal structure of $\alpha$-anomer, O-(2,3,4,6-tetra-O-acetyl$\alpha$-D-mannopyranosyl)-(4R,5R)-2,2-dimethyl-1,3-dioxolane-4,5dicarboxylate $7 \mathrm{c}$.

$-97.4(4)^{\circ}, \mathrm{C} 17-\mathrm{O} 14-\mathrm{C} 19-\mathrm{O} 15=-5.3(7)^{\circ}, \mathrm{C} 17-\mathrm{O} 14-\mathrm{C} 19-\mathrm{C} 21=$ 109.3(8) ${ }^{\circ}, \mathrm{C} 17-\mathrm{O} 14-\mathrm{C} 19-\mathrm{C} 20=-123.6(6)^{\circ}, \mathrm{C} 16-\mathrm{O} 15-\mathrm{C} 19-\mathrm{O} 14$ $=-4.3(6)^{\circ}, \mathrm{C} 16-\mathrm{O} 15-\mathrm{C} 19-\mathrm{C} 21=-121.1(8)^{\circ}$, and C16-O15-C19$\mathrm{C} 20=113.7(6)^{\circ}$. 
TABLE 2: Coupling conditions and isolated yield for $\mathbf{5 a}-\mathbf{e}$ and $\mathbf{7 a}-\mathbf{e}$.

\begin{tabular}{|c|c|c|c|c|c|c|}
\hline \multirow{2}{*}{$\begin{array}{l}\text { Entry } \\
1\end{array}$} & \multicolumn{2}{|c|}{ Starting material } & \multirow{2}{*}{$\frac{\text { Reagents/conditions }}{1.3 \text { eq. EDC, cat. DMAP, r.t., } 12 \mathrm{~h}}$} & \multirow{2}{*}{$\begin{array}{c}\text { Product (isolated yield\%) } \\
72\end{array}$} & \multirow{2}{*}{$\begin{array}{l}\alpha: \beta \\
\text { ratio } \\
0: 1\end{array}$} & \multirow{2}{*}{$\frac{[\alpha]_{\mathrm{D}}^{25}}{12.5}$} \\
\hline & $4 a$ & HA & & & & \\
\hline 2 & $4 b$ & HA & 1.3 eq. EDC, cat. DMAP, r.t., $12 \mathrm{~h}$ & 69 & $0: 1$ & 13.3 \\
\hline 3 & $4 c$ & HA & 1.3 eq. EDC, cat. DMAP, r.t., $12 \mathrm{~h}$ & 65 & $0: 1$ & 27.1 \\
\hline 4 & $4 d$ & $\mathrm{HA}$ & 1.3 eq. EDC, cat. DMAP, r.t., $12 \mathrm{~h}$ & 67 & $0: 1$ & 43.3 \\
\hline 5 & $4 e$ & HA & 1.3 eq. EDC, cat. DMAP, r.t., $12 \mathrm{~h}$ & 68 & $0: 1$ & 47.1 \\
\hline 6 & $6 a$ & $\mathrm{HA}$ & 1.3 eq. EDC, cat. DMAP, r.t., 18 h & 72 & $1: 3$ & 26.5 \\
\hline 7 & $6 b$ & HA & 1.3 eq. EDC, cat. DMAP, r.t., $18 \mathrm{~h}$ & 74 & $1: 3$ & 21.6 \\
\hline 8 & $6 c$ & HA & 1.3 eq. EDC, cat. DMAP, r.t., $18 \mathrm{~h}$ & 70 & $1: 1$ & 17.3 \\
\hline 9 & 6d & HA & 1.3 eq. EDC, cat. DMAP, r.t., $18 \mathrm{~h}$ & 67 & $1: 3$ & 45.0 \\
\hline 10 & $6 e$ & HA & 1.3 eq. EDC, cat. DMAP, r.t., $18 \mathrm{~h}$ & 63 & $1: 3$ & 33.3 \\
\hline
\end{tabular}

$c=24 \mathrm{mg} / 2 \mathrm{~mL}$ in dichloromethane.

TABLE 3: \% inhibition of compounds $\mathbf{5 a}-\mathbf{e}$ and $\mathbf{7 a}-\mathbf{e}$ against $L$. tropica leishmania.

\begin{tabular}{|c|c|c|c|}
\hline Compound & L. tropica $^{\mathrm{a}}$ & Compound & L. tropica ${ }^{\mathrm{a}}$ \\
\hline $5 \mathrm{a}$ & $0.65 \pm 0.01$ & $7 a$ & $1.35 \pm 0.04$ \\
\hline $5 b$ & $0.68 \pm 0.09$ & $7 \mathbf{b}$ & $0.73 \pm 0.12$ \\
\hline $5 c$ & $0.81 \pm 0.16$ & $7 \mathrm{c}$ & $0.63 \pm 0.18$ \\
\hline $5 d$ & $0.68 \pm 0.27$ & $7 d$ & $0.77 \pm 0.08$ \\
\hline \multirow[t]{3}{*}{$5 e$} & $0.89 \pm 0.11$ & $7 e$ & $0.66 \pm 0.18$ \\
\hline & Standard drug $\mathrm{IC}_{50}$ & $(\mu \mathrm{g} / \mathrm{mL} \pm \mathrm{SD})$ & \\
\hline & Amphotericin B & $0.56 \pm 0.20$ & \\
\hline
\end{tabular}

${ }^{a}$ Percentage inhibition activity: $100=$ (nonsignificant; $0.95-0.80=$ low; $0.79-0.70=$ moderate; $0.69-0.60=$ good; below $0.59-0.56=$ significant activity).

\section{Material and Methods}

4.1. Antileishmanial Activity. Antileishmanial activities of compounds $5 \mathbf{a}-\mathbf{e}$ and $7 \mathbf{a}-\mathbf{e}$ were assayed by Zhai et al.s method (1999) [32] using a preestablished culture of Leishmania. Triple-N media slants were overlaid with 199 media for leishmanial growth. NNN medium was prepared by mixing $4 \mathrm{~g}$ of agar in $100 \mathrm{~mL}$ of distilled water. The mixture was then dissolved and sterilized by autoclaving at $121^{\circ} \mathrm{C}$ and then allowed to cool to $55^{\circ} \mathrm{C}$. $15-20 \mathrm{~mL}$ of defibrinated sheep blood was aseptically added to the mixture with gentle rolling with glass beads; 1 ampoule of gentamicin was mixed in blood and mixed with the agar mixture. Slopes of culture medium were prepared by dispensing $2-3 \mathrm{~mL}$ of the blood agar mixture into sterile tubes that were then set in a slant position until the agar completely solidified. To prepare 199 medium different constituents were mixed in $1000 \mathrm{~mL}$ of distilled water. The $\mathrm{pH}$ was adjusted to 7.4 and medium was filtered, sterilized, and kept at $37^{\circ} \mathrm{C}$ for $24 \mathrm{~h}$ to check sterility. Preestablished culture of Leishmania tropica KWH23 was inoculated in 199 medium in Triple- $\mathrm{N}$ medium slants and incubated at $24^{\circ} \mathrm{C}$ for 6-7 days and the results are summarized in Table 3 .

\section{Results}

All the synthesized $N$-linked $5 \mathbf{a}-\mathbf{e}$ and $O$-linked glycopyranosides $7 \mathbf{a}-\mathbf{e}$ were tested for their antileishmanial activity using Leishmania tropica KWH23 promastigotes for in vitro screening. The results are shown in Table 3. Compounds 5a, $\mathbf{5 b}$, and $\mathbf{5 d}$ showed good activity while the compounds $\mathbf{5 c}$ and 5e exhibited low activity.

Among the synthesized O-linked glycopyranosides 7a-7e, compounds $7 \mathbf{c}$ and $7 \mathbf{e}$ showed good activity; $7 \mathbf{b}$ and $\mathbf{7 d}$ showed moderate activity. Compound $7 \mathbf{a}$ showed nonsignificant activity.

\section{Conclusion}

Most of the synthesized compounds $5 \mathbf{a}-\mathbf{e}$ and $7 \mathbf{a}-\mathbf{e}$ showed moderate to good activities against Leishmania tropica KWH23 promastigotes. Compounds $\mathbf{5 a}, \mathbf{5 b}$, and $\mathbf{5 d}$ were the most active. Among the synthesized compounds, 7a-7e, 7c, and $7 \mathbf{e}$ were more active than $7 \mathbf{a}, 7 \mathbf{b}$, and $\mathbf{7 d}$. Drug resistance has been reported in various species of Leishmania against various antileishmanial drugs like antimonials, amphotericin $\mathrm{B}$, pentamidine, miltefosine, and so forth. In this scenario these synthetic compounds may be further explored for research in medicinal chemistry and drug designing. These compounds may prove to be good candidates against leishmaniasis. A number of other new compounds can also be synthesized while following the same $\mathrm{N}$ - and $\mathrm{O}$-acylation synthetic routes. Such compounds can act as valuable glycodrugs as many of the glycosides and their derivatives have been reported to be biologically active compounds. 


\section{Conflicts of Interest}

The authors confirm that this article's content has no conflicts of interest.

\section{Acknowledgments}

This work was financially supported by Higher Education Commission (HEC), Pakistan, under International Research Support Initiative Program (IRSIP) and National Research Program (NRPU) for Universities.

\section{Supplementary Materials}

Supplementary data include NMR $\left({ }^{1} \mathrm{H}\right.$ and $\left.{ }^{13} \mathrm{C}\right), \mathrm{IR}$, and MS spectra of the synthesized compounds (5a-5d and $7 \mathbf{a}-7 \mathbf{e})$. ${ }^{1} \mathrm{HNMR}$ of compound 5a. ${ }^{13} \mathrm{CNMR}$ of compound 5a. ESIMS of compound 5a. FT-IR of compound 5a. ${ }^{1} \mathrm{HNMR}$ of compound $\mathbf{5 b}$. ${ }^{13} \mathrm{CNMR}$ of compound $\mathbf{5 b}$. ESI-MS of compound $\mathbf{5 b}$. ${ }^{1} \mathrm{HNMR}$ of compound $5 \mathbf{c} .{ }^{13} \mathrm{CNMR}$ of compound $5 c$. ${ }^{1} \mathrm{HNMR}$ of compound $5 \mathrm{~d} .{ }^{13} \mathrm{CNMR}$ of compound 5d. ESI-MS of compound 5d. ${ }^{1} \mathrm{HNMR}$ of compound 7a. ${ }^{13} \mathrm{CNMR}$ of compound $7 \mathbf{a}$. ESI-MS of compound $7 \mathbf{a}$. ${ }^{1} \mathrm{HNMR}$ of compound $7 \mathbf{b} .{ }^{13} \mathrm{CNMR}$ of compound $7 \mathbf{b}$. ESIMS of compound $\mathbf{7 b}$. ESI-MS of compound $\mathbf{7 b}$ backup. ${ }^{1}$ HNMR of compound $7 c$, new. ${ }^{1}$ HNMR of compound $7 c$. ${ }^{13} \mathrm{CNMR}$ of compound $7 \mathrm{c} .{ }^{13} \mathrm{CNMR}$ of compound $\mathbf{7 b}$, new. ESI-MS of compound 7c. Mass analysis of compound 7c. ${ }^{1}$ HNMR of compound $7 \mathbf{d} .{ }^{13}$ CNMR of compound $7 \mathbf{d}$. ESI-MS of compound $\mathbf{7 d}$. Mass analysis of compound $\mathbf{7 d}$. ${ }^{1} \mathrm{HNMR}$ of compound $7 \mathbf{e} .{ }^{13} \mathrm{CNMR}$ of compound $7 \mathbf{e}$. (Supplementary Materials)

\section{References}

[1] N. Singh, B. B. Mishra, S. Bajpai, R. K. Singh, and V. K. Tiwari, "Natural product based leads to fight against leishmaniasis," Bioorganic \& Medicinal Chemistry, vol. 22, no. 1, pp. 18-45, 2014.

[2] P. Dwivedi, K. B. Mishra, B. B. Mishra, N. Singh, R. K. Singh, and V. K. Tiwari, "Click inspired synthesis of antileishmanial triazolyl O-benzylquercetin glycoconjugates," Glycoconjugate Journal, vol. 32, no. 3-4, pp. 127-140, 2015.

[3] B. B. Mishra, J. K. Gour, N. Kishore, R. K. Singh, V. Tripathi, and V. K. Tiwari, "An antileishmanial prenyloxy-naphthoquinone from roots of plumbago zeylanica," Natural Product Research (Formerly Natural Product Letters), vol. 27, no. 4-5, pp. 480-485, 2013.

[4] W. B. Leishman, "On the possibility of the occurrence of trypanosomiasis in India," British Medical Journal, vol. 1, no. 2213, pp. 1252-1254, 1903.

[5] C. Donovan, "On the possibility of the occurrence of trypanosomia-sis in India," British Medical Journal, vol. 2, pp. 79-82, 1903.

[6] C. Nicolle and C. Comte, "Origine canine du Kala-azar," Bulletin So-ciété Pathologie Exotique, vol. 1, pp. 299-301, 1908.

[7] WHO (World Health Organisation), "Communicable disease sur-veillance and response," http://www.who.int/emc/diseases/ leish/leisdis1.html.

[8] S. L. Croft, "The current status of antiparasite chemotherapy," Parasitology, vol. 114, no. 1, pp. S3-S15, 1997.
[9] H. D. Engers, R. Bergquist, and F. Moddaber, "Progress on vaccines against parasite," Developments in Biological Standardization, vol. 87, pp. 73-84, 1996.

[10] H. Hojo and N. Nakahara, "Recent Progress in the Solid-phase Synthesis of Glycopeptide," Current Protein \& Peptide Science, vol. 1, no. 1, pp. 23-48, 2000.

[11] H. Lis and N. Sharon, "Protein glycosylation: structural and functional aspects," European Journal of Biochemistry, vol. 218, no. 1, pp. 1-27, 1993.

[12] A. Varki, "Biological roles of oligosaccharides: all of the theories are correct," Glycobiology, vol. 3, no. 2, pp. 97-130, 1993.

[13] S.-Y. Han and Y.-A. Kim, "Recent development of peptide coupling reagents in organic synthesis," Tetrahedron, vol. 60, no. 11, pp. 2447-2467, 2004.

[14] R. B. Greenwald, H. Zhao, J. Xia, and A. Martinez, "Poly(ethylene glycol) transport forms of vancomycin: a long-lived continuous release delivery system," Journal of Medicinal Chemistry, vol. 46, no. 23, pp. 5021-5030, 2003.

[15] C. Dai, D. Li, J. Popovici-Muller et al., "2-(2-Aminothiazol-4yl)pyrrolidine-based tartrate diamides as potent, selective and orally bioavailable TACE inhibitors," Bioorganic and Medicinal Chemistry Letters, vol. 21, no. 10, pp. 3172-3176, 2011.

[16] J.-B. Behr, T. Gourlain, A. Helimi, and G. Guillerm, "Design, synthesis and biological evaluation of hetaryl-nucleoside derivatives as inhibitors of chitin synthase," Bioorganic \& Medicinal Chemistry Letters, vol. 13, no. 10, pp. 1713-1716, 2003.

[17] A. Dahlgren, J. Branalt, I. Kvarnström, I. Nilsson, D. Musil, and B. Samuelsson, "Synthesis of potential thrombin inhibitors. Incorporation of tartaric acid templates as $\mathrm{P} 2$ proline mimetics," Bioorganic and Medicinal Chemistry, vol. 10, no. 5, pp. 15671580, 2002.

[18] H. B. Küçük, A. Yusufoğlu, E. Mataraci, and S. Dösler, "Synthesis and biological activity of new 1,3-dioxolanes as potential antibacterial and antifungal compounds," Molecules, vol. 16, no. 8, pp. 6806-6815, 2011.

[19] S. Li, G. Liao, J. Xiao et al., "Derivatives of substituted tartaric acid and usage for preparing beta-secretase inhibitors," US 8268884 B2, 2012.

[20] B. B. Mishra and V. K. Tiwari, "Natural products: an evolving role in future drug discovery," European Journal of Medicinal Chemistry, vol. 46, no. 10, pp. 4769-4807, 2011.

[21] Siemens, SMART and SAINT, Siemens Analytical X-Ray Instruments Inc., Madison, Wisconsin, USA, 1996.

[22] A. Altomare, G. Cascarano, C. Giacovazzo, and A. Guagliardi, "Completion and refinement of crystal structures with SIR92," Journal of Applied Crystallography, vol. 26, no. 3, pp. 343-350, 1993.

[23] G. M. Sheldrick, SHELXTL-PC (Version 5.1), Siemens analytical instruments, Inc., Madison, Wisconsin, Wis, 1997.

[24] C. K. Jhnson, ORTEPII Report ORNL-5138, Oak Ridge National Laboratory, Tennessee, Tenn, USA, 1976.

[25] L. M. Likhosherstov, O. S. Novikova, V. A. Derevitskaja, and N. K. Kochetkov, "A new simple synthesis of amino sugar $\beta$-dglycosylamines," Carbohydrate Research, vol. 46, no. 1, pp. C1C5, 1986 .

[26] P. J. Garegg, "Saccharides of biological importance: challenges and opportunities for organic synthesis," Accounts of Chemical Research, vol. 25, no. 12, pp. 575-580, 1992.

[27] H. J. Berthold, S. Franke, J. Thiem, and T. Schotten, "Ex post glycoconjugation of phthalocyanines," The Journal of Organic Chemistry, vol. 75, no. 11, pp. 3859-3862, 2010. 
[28] V. V. Sureshbabu, R. Venkataramanarao, and H. P. Hemantha, "A facile synthesis of C-terminal neoglycopeptides: incorporation of urea moiety between sugars and peptides employing curtius rearrangement," International Journal of Peptide Research and Therapeutics, vol. 14, no. 1, pp. 34-40, 2008.

[29] T. Ren and D. Liu, "Synthesis of targetable cationic amphiphiles," Tetrahedron Letters, vol. 40, no. 43, pp. 7621-7625, 1999.

[30] R. R. Schmidt, "New methods for the synthesis of glycosides and oligosaccharides-are there alternatives to the koenigs-knorr method?" Angewandte Chemie International Edition, vol. 25, no. 3, pp. 212-235, 1986.

[31] G. Excoffier, D. Gagnaire, and J.-P. Utille, "Coupure sélective par l'hydrazine des groupements acétyles anomères de résidus glycosyles acétylés," Carbohydrate Research, vol. 39, no. 2, pp. 368-373, 1975.

[32] L. Zhai, M. Chen, J. Blom, T. G. Theander, S. B. Christensen, and A. Kharazmi, "The antileishmanial activity of novel oxygenated chalcones and their mechanism of action," Journal of Antimicrobial Chemotherapy, vol. 43, no. 6, pp. 793-803, 1999. 

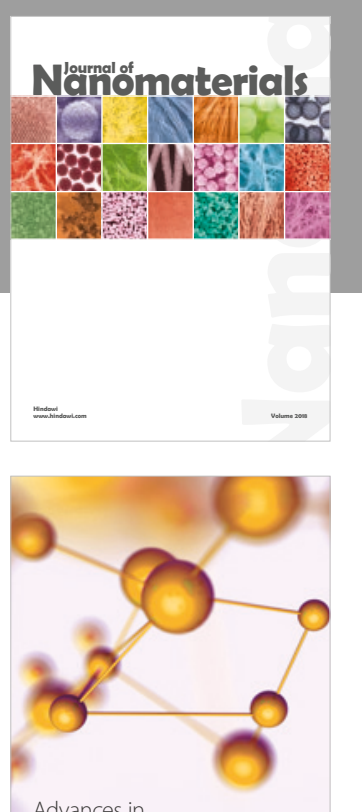

Physical Chemistry
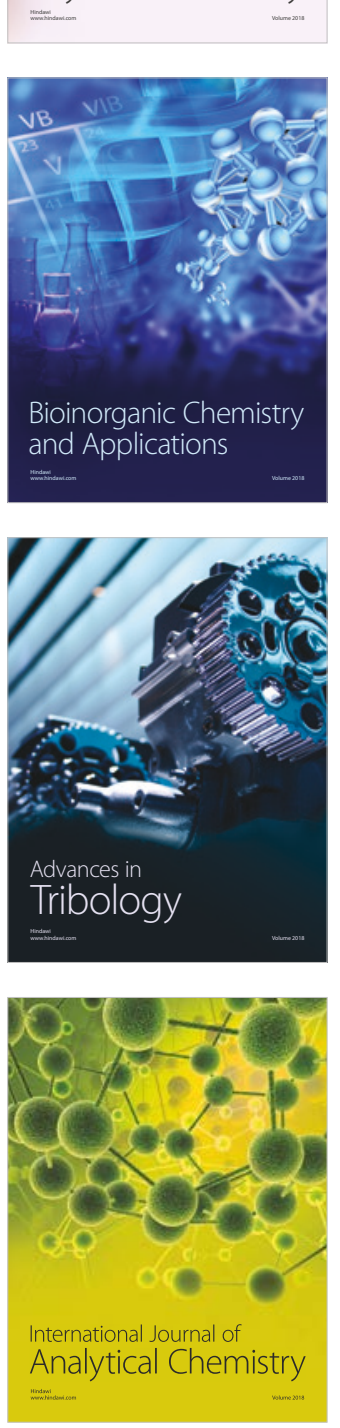

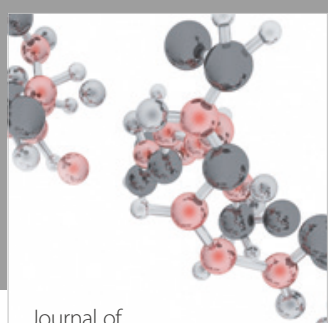

Analytical Methods

in Chemistry

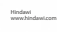

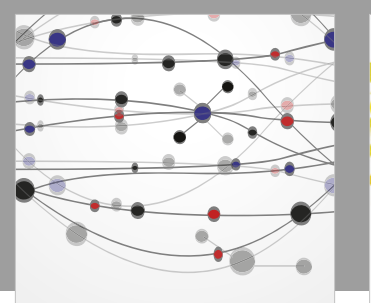

The Scientific World Journal

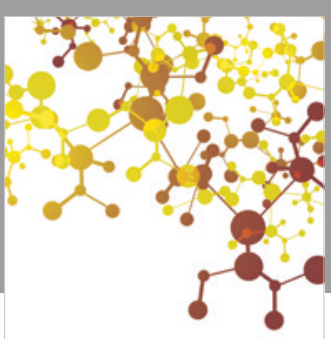

Journal of

Applied Chemistry
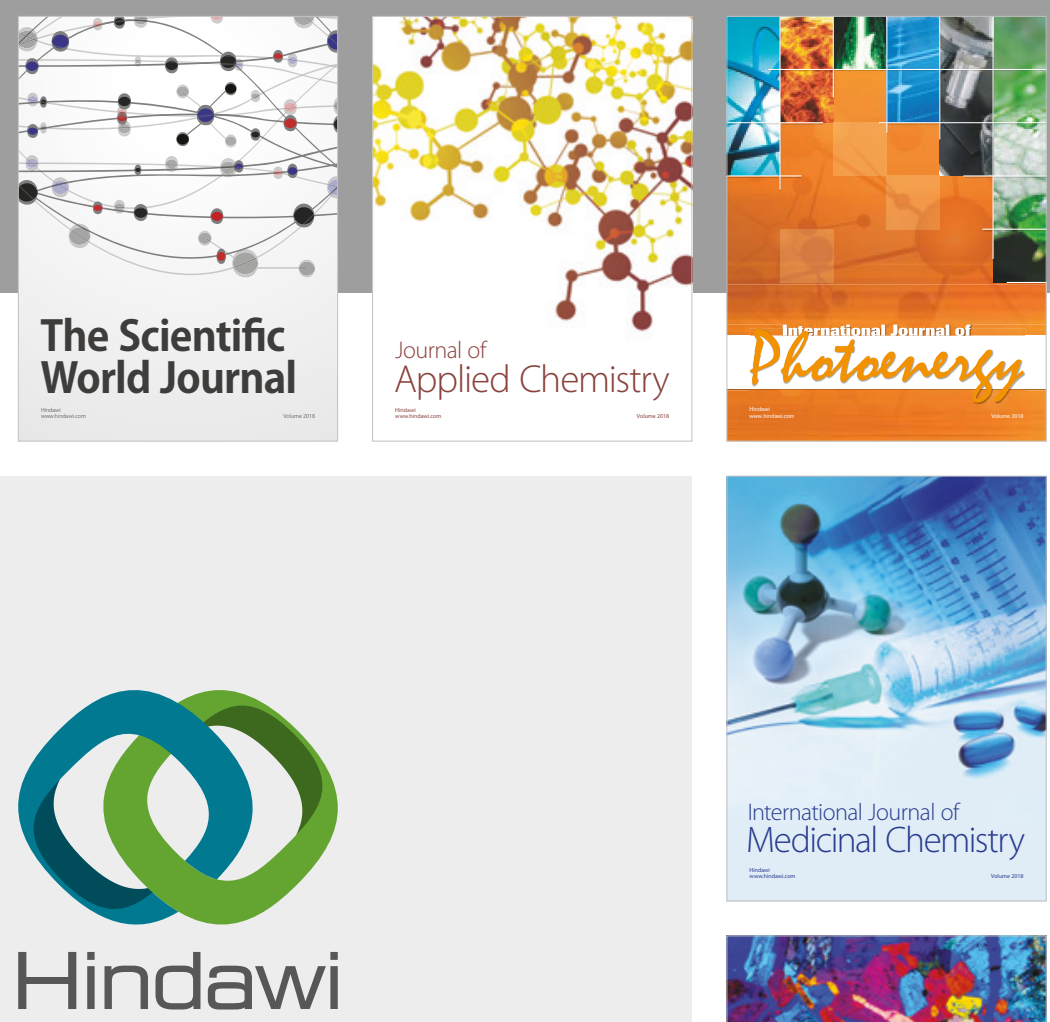

Submit your manuscripts at

www.hindawi.com
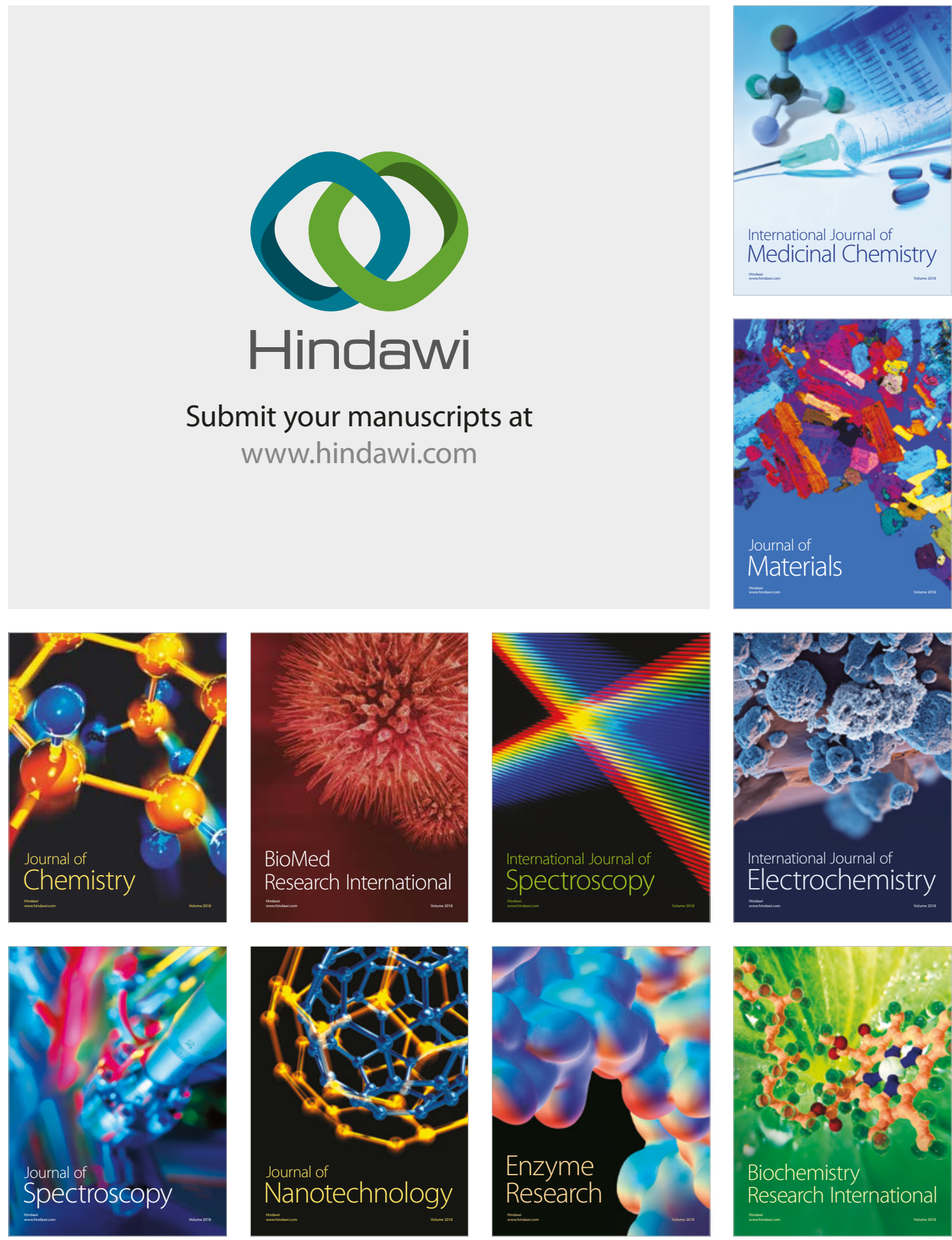
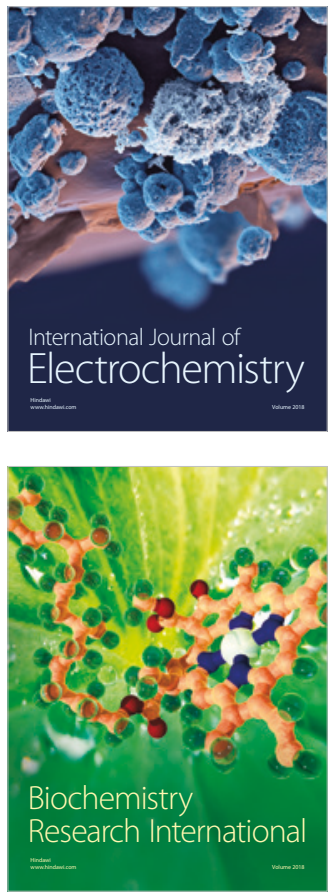